\title{
Seasonal and diurnal variation of lightning activity over southern Africa and correlation with European whistler observations
}

\author{
A. B. Collier ${ }^{1,2}$, A. R. W. Hughes ${ }^{1}$, J. Lichtenberger ${ }^{3}$, and P. Steinbach ${ }^{4}$ \\ ${ }^{1}$ School of Physics, University of KwaZulu-Natal, 4041, Durban, South Africa \\ ${ }^{2}$ Alfvén Laboratory, Royal Institute of Technology, SE-100 44, Stockholm, Sweden \\ ${ }^{3}$ Space Research Group, Eötvös University, Budapest, Pf 32, H-1518, Hungary \\ ${ }^{4}$ Research Group for Geoinformatics and Space Sciences, Eötvös University, Budapest, Pf 32, H-1518 Hungary \\ Received: 21 July 2005 - Revised: 5 December 2005 - Accepted: 10 January 2006 - Published: 23 March 2006
}

\begin{abstract}
Lightning Imaging Sensor (LIS) data have been analysed to ascertain the statistical pattern of lightning occurrence over southern Africa. The diurnal and seasonal variations are mapped in detail. The highest flash rates $\left(107.2 \mathrm{~km}^{-2} \mathrm{y}^{-1}\right)$ occur close to the equator but maxima are also found over Madagascar $\left(32.1 \mathrm{~km}^{-2} \mathrm{y}^{-1}\right)$ and South Africa $\left(26.4 \mathrm{~km}^{-2} \mathrm{y}^{-1}\right)$. A feature of the statistics is a relatively steady contribution from over the ocean off the east coast of South Africa that appears to be associated with the Agulhas current.

Lightning statistics are of intrinsic meteorological interest but they also relate to the occurrence of whistlers in the conjugate region. Whistler observations are made at Tihany, Hungary. Statistics reveal that the period of most frequent whistler occurrence does not correspond to the maximum in lightning activity in the conjugate region but is strongly influenced by ionospheric illumination and other factors. The whistler/flash ratio, $R$, shows remarkable variations during the year and has a peak that is narrowly confined to February and March.
\end{abstract}

Keywords. Meteorology and atmospheric dynamics (Lightning) - Radio science (Radio wave propagation)

\section{Introduction}

Whistlers are dispersed Very Low Frequency (VLF) electromagnetic signatures of lightning discharges, received after propagating through the magnetosphere in field-aligned ducts of enhanced plasma density (Helliwell, 1965). They usually originate from discharges in the conjugate hemisphere. This is particularly true at low latitudes; at higher latitudes the signal may echo back and forth between hemispheres. The occurrence rate of whistlers is very much

Correspondence to: A. B. Collier

(colliera@ukzn.ac.za) lower than the rate of conjugate lightning discharges, and so it is of interest to know which factors determine the reception of a whistler. With this in mind we present statistics relating to the temporal and geographical distribution of lightning over southern Africa and the whistler detection rate at an observatory in Europe. This provides an opportunity to explore the correlation between whistler occurrence and lightning activity in the conjugate region. An attempt to obtain a better understanding of lightning as a source mechanism is motivated by the fact that whistlers may act as a remote sensing tool for magnetospheric plasma and the role that they play in the loss of electrons from the inner radiation belt (Green et al., 2005; Rodger et al., 2004b). It should be noted that since the VLF observations presented here were obtained from the ground they pertain to ducted whistlers and the significant population of non-ducted signals, which have an extensive impact on the radiation belts (Lauben et al., 1999; Johnson et al., 1999), are not considered.

Lightning may be classified as either cloud-to-ground (CG) or cloud-to-cloud (CC), where the latter outnumber the former by a ratio of at least 6:1 (Preston-Whyte and Tyson, 1988). The empirical relationship of Prentice and Mackerras (1977) suggests that this ratio may be as high as 6.3:1 near the equator, dropping to $4.2: 1$ at a latitude of $30^{\circ}$. Different lightning detection systems may be optimised to detect either class of discharge.

A single lightning flash is comprised of one or more component strokes (Malan, 1963), each of which constitutes a brief transfer of charge. The highest peak currents are generally associated with the first few strokes in a multicomponent flash. Individual strokes radiate electromagnetic energy and thus each may independently be the source of a whistler. Lightning detection systems in general detect individual strokes, however, some, like LIS, associate groups of strokes into flashes. 
Favourable conditions for lightning are intimately linked to atmospheric temperature gradients. Small differences in atmospheric temperature cause local departures from hydrostatic equilibrium. The buoyancy of the resulting unstable air drives the formation of thunder clouds. The principal factors involved in thunder cloud creation are warm surface air and the presence of moisture. Geographical features also play a role: plain-mountain winds, for instance, blowing during the day, contribute to the evolution of storm systems over heated high ground. The seasonal variation in surface air temperature depends on the length of the day and the maximum altitude of the Sun, implying that spring and summer are most conducive to thunderstorm activity (Christian et al., 2003). The diurnal heating of surface air also modulates the level of convection and thunderstorm production.

The relative motion of water droplets and ice particles within a thunder cloud leads to charge separation. A lightning discharge results when the potential gradient within a cloud or between the cloud and ground exceeds a critical threshold. The non-linear relationship between cloud electrification and buoyancy implies that the level of lightning activity may be a sensitive indicator of global temperature change (Williams, 1992), although this effect might be difficult to detect (for example, Watkins et al., 2001). The presence of factors appropriate to the formation of storm cells should also be reflected in the distribution of lightning.

Anderson et al. (1984) used an array of 380 lightning detectors distributed throughout South Africa and Namibia to assess the distribution of lightning in the region. They found areas in which the flash density achieved rates greater than $12 \mathrm{~km}^{-2} \mathrm{y}^{-1}$. Their instruments, however, discriminated against $\mathrm{CC}$ strokes and were predominantly situated in locations with high keraunic (thunderstorm activity) levels.

Within southern Africa Christian et al. (2003) found flash rate densities as high as $82.7 \mathrm{~km}^{-2} \mathrm{y}^{-1}$ close to the equator, and $23.0 \mathrm{~km}^{-2} \mathrm{y}^{-1}$ for Bloemfontein, South Africa. Data from a time-of-arrival lightning detection network in South Africa suggests that the CG flash rate density varies from low levels over the Cape to in excess of $12 \mathrm{~km}^{-2} \mathrm{y}^{-1}$ over the highveld (Ndlovu and Evert, private communication, 2004), which is the high plateau region of South Africa. The nominal detection efficiency of this terrestrial network, which is optimised for CG strokes, varies appreciably across the country, from greater than $90 \%$ on the highveld to less than $40 \%$ in the Cape.

The lightning statistics presented here are derived from the Lightning Imaging Sensor (LIS) instrument which is part of the scientific payload on the Tropical Rainfall Measuring Mission (TRMM) observatory. TRMM was launched during November 1997 into an orbit with $35^{\circ}$ inclination and an initial altitude of $350 \mathrm{~km}$. LIS is the successor to the Optical Transient Detector (OTD) instrument, which was operational between April 1995 and March 2000. The LIS/OTD data have been used to examine the statistical distribution of lightning discharges on a global (Christian et al., 2003) and regional (Kandalgaonkar et al., 2003) scale. LIS was designed to detect terrestrial lightning activity. For each detected lightning event the instrument records the time of occurrence, measured radiant energy and estimated location. Lightning events are clustered into multiple stroke flashes or isolated single stroke flashes according to their temporal and spatial proximity. LIS has a $580 \mathrm{~km} \times 580 \mathrm{~km}$ field-of-view with spatial resolution of between 3.9 and $5.4 \mathrm{~km}$ at nadir and limb respectively (Christian et al., 2000). The data are organised in $0.5^{\circ} \times 0.5^{\circ}$ cells. During a single orbit LIS can observe a given point on the Earth's surface for between 80 and $85 \mathrm{~s}$ with $2 \mathrm{~ms}$ time resolution. The imaging system, which incorporates a narrow-band filter centred on the $777.4 \mathrm{~nm}$ emission line of neutral atomic oxygen (Koshak et al., 2000), employs sophisticated techniques to detect lightning discharges even in the presence of bright background from sunlit clouds. The resulting detection efficiency is around $90 \%$. LIS is capable of detecting both CC and CG discharges, but does not distinguish between them. This distinction may, however, be significant for the generation of whistlers.

Since the duration of LIS coverage of a particular region on any given day is limited, data from the World Wide Lightning Location Network (WWLLN) may be used to obtain an impression of the lightning activity in that area which is continuous in time. The WWLLN operates on the Time of Group Arrival (TOGA) principle described by Dowden et al. (2002). A reliable location fix requires that a stroke be registered by at least four stations with a residual of less than $30 \mu$ s (Rodger et al., 2004a, 2005). These criteria were applied in selecting the WWLLN data presented here. The network does not at present achieve a very high level of efficiency since there are only a limited number of stations distributed over the globe. Rodger et al. (2005) estimate that WWLLN currently detects $2 \%$ of global lightning and $5 \%$ of global CG lightning. WWLLN stations are operated at the University of KwaZulu-Natal (UKZN) and Eötvös University as well as a number of other locations.

Continuous VLF measurements are routinely made at an observatory in Tihany, Hungary $\left(46.89^{\circ} \mathrm{N} 17.89^{\circ} \mathrm{E}, 200 \mathrm{~m}\right.$, $L=1.81$ ), where an automatic detection system developed by the group at Eötvös University records the occurrence of whistlers. The magnetic conjugate point of the observatory (2001 epoch) is located at $33.45^{\circ} \mathrm{S} 28.34^{\circ} \mathrm{E}$, near East London, South Africa. Seasonal and diurnal variations in the lightning activity in the region surrounding the conjugate point should be reflected in the frequency of whistler detection at Tihany. Naturally, lightning activity is not the only factor influencing the generation of whistlers - the presence of ducts and ionospheric conditions also play a role - but as lightning constitutes the source of the phenomenon, one would expect it to be a significant factor.

The lightning study domain, which includes the whole of southern Africa, incorporating longitudes from the prime meridian to $60^{\circ} \mathrm{E}$ and latitudes from $38^{\circ} \mathrm{S}$ to the equator, is displayed in Fig. 1a. The area of this region, $26.2 \times 10^{6} \mathrm{~km}^{2}$, 
of which $36 \%$ is land, is only $5 \%$ of the Earth's total surface area. The mapping of southern African boundaries across the geomagnetic equator to the Northern Hemisphere is given in Fig. 1b. It is apparent that the study region maps to central and southern Europe as well as north Africa and the middle east.

For the purpose of this study an area of $600 \mathrm{~km}$ radius centred on Tihany's conjugate point was considered as the whistler source location. The size of the whistler source region was selected fairly arbitrarily but is considered large enough to take into account uncertainties in both the location of the actual conjugate point and the size of the surrounding area in which lightning strokes are most likely to excite a duct. Furthermore, this represents the largest circular region surrounding the conjugate point which lies completely within the range of latitudes covered by LIS. A larger source region of $900 \mathrm{~km}$ radius was also attempted, but in this case it was necessary to displace the centre $300 \mathrm{~km}$ northwards in order that it remain within the range of latitudes covered by LIS. Although this resulted in a significantly higher number of lightning strokes within the source region, the general conclusions were unaltered.

A reasonable value for the extent of the source region is a contentious issue and must be a compromise between the need to localise the origin of the whistler signals and not disregard the fact that the signal may propagate an appreciable distance in the Earth-ionosphere waveguide before entering a duct (Clilverd et al., 1992), although this may represent rather exceptional circumstances. Weidman et al. (1983) observed whistlers with a maximum excitation range greater than $2200 \mathrm{~km}$. Carpenter and Orville (1989) found that although whistlers were sometimes excited by lightning strokes at distances greater that $2500 \mathrm{~km}$ from the duct footprint, a significant fraction - between one quarter and one half - were produced by lightning in closer proximity to the duct. It is also possible that a whistler may be trapped in a duct after leaking in through its side rather than entering at the base (Strangeways and Rycroft, 1980; Strangeways et al., 1982).

Since the power of a signal radiating symmetrically in the Earth-ionosphere waveguide is inversely proportional to the distance from the source, it is not unreasonable to suppose that the likelihood of duct excitation by a given lightning stroke is highest in close proximity to the stroke. Consequently one would suppose that a region of limited extent around the conjugate point represents the area in which a whistler's causative stroke is most likely to be located. Certainly this is a reasonable assumption if there is an appreciable level of lightning activity in the vicinity of the conjugate point, which is certainly the case for Tihany. If, however, the conjugate point is located in a region of infrequent lightning then it is probable that a realistic source region should have considerably greater size. (a)

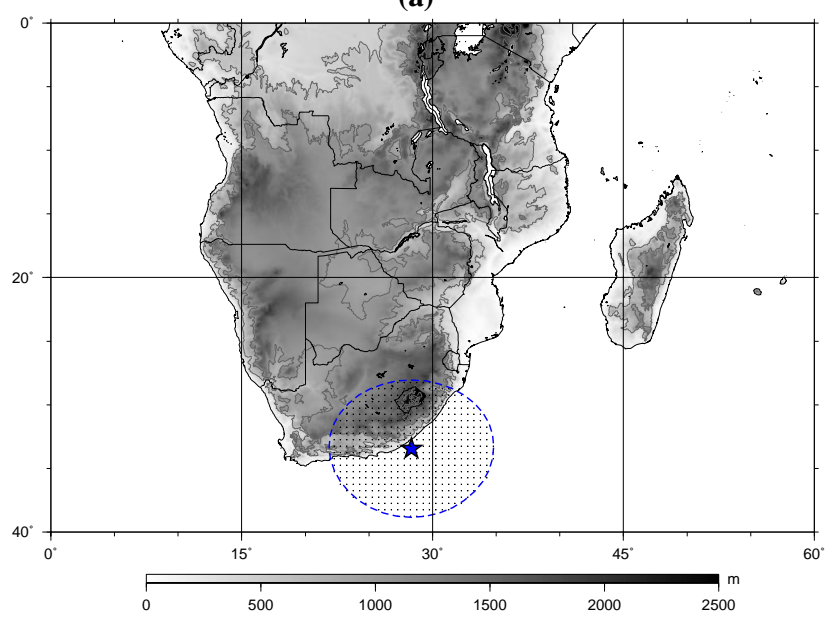

(b)

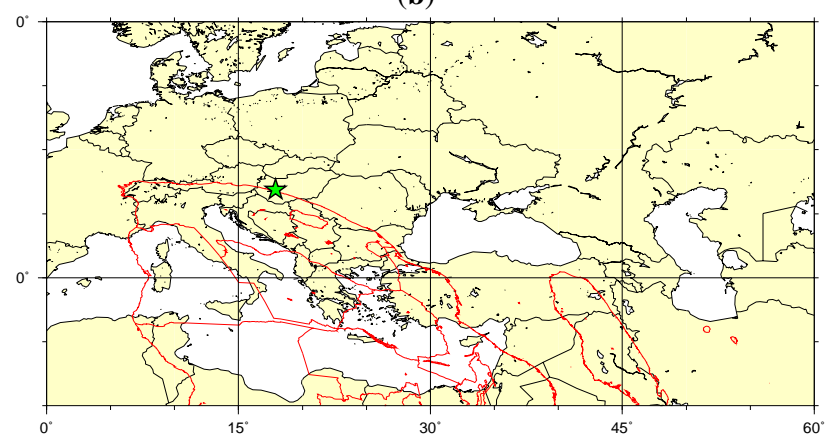

Fig. 1. Geographic regions under consideration. (a) Topography of southern Africa. The altitude data was obtained from the USGS global digital elevation model (http://edcdaac.usgs.gov/ gtopo30/gtopo30.asp). Tihany's conjugate point is indicated by the blue star. The nominal whistler source region is located within the dashed circle of radius $600 \mathrm{~km}$ centred on the conjugate point. (b) Europe with overlay of magnetic conjugates of southern African geographic and national boundaries. The location of Tihany is indicated by the green star.

The total area of the 443 cells within the whistler source region is $1.14 \times 10^{6} \mathrm{~km}^{2}$, which is $4.2 \%$ of the study area. Of this area $4.11 \times 10^{5} \mathrm{~km}^{2}$ is land, while the balance, $7.30 \times 10^{5} \mathrm{~km}^{2}$, is over the ocean.

\section{Lightning statistics}

The lightning data presented here are for the period 1 January 1999 to 31 December 2004. During this interval LIS made 34337 orbits of $\sim 90$ min duration, 22312 of which passed through the study domain. A total time of $293387 \mathrm{~min}$ was spent over the study region, equivalent to 34 days per year. Although the LIS data does extend slightly further poleward than $38^{\circ} \mathrm{S}$ the sampling is extremely sparse and consequently the data were truncated at this latitude. 


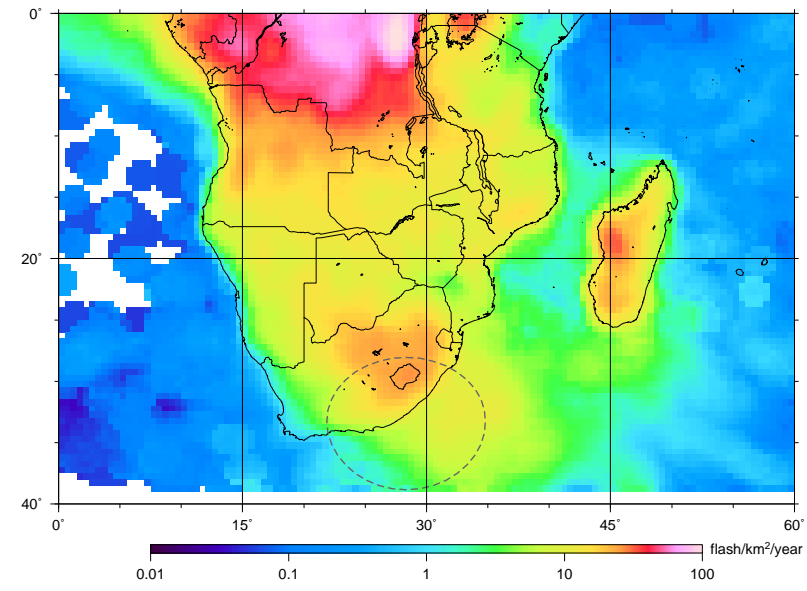

Fig. 2. Annualised flash rate density over southern Africa.

Considering first the entire study domain, Fig. 2 displays the annualised flash rate density over southern Africa, calculated as the ratio of the number of flashes in a cell to the product of the total viewing time and area of that cell. The colour scale in Fig. 2 is in units of $\mathrm{km}^{-2} \mathrm{y}^{-1}$. The flash density was weighted by the reciprocal of the LIS flash detection efficiency as estimated by Christian et al. (2003), which is a function of local time, with a minimum at midday. The data was then smoothed with a $300 \mathrm{~km}$ full width boxcar filter. The mean flash density within the study region is $19.2 \mathrm{~km}^{-2} \mathrm{y}^{-1}$ and $1.7 \mathrm{~km}^{-2} \mathrm{y}^{-1}$ over land and ocean, respectively. The former figure is higher than the global mean land density of $8.3 \mathrm{~km}^{-2} \mathrm{y}^{-1}$ obtained by Mackerras et al. (1998), a result tempered by the relatively low level of activity over Asia. The peak flash density of $107.2 \mathrm{~km}^{-2} \mathrm{y}^{-1}$ was found in the tropics. Two secondary maxima were located over Madagascar $\left(32.1 \mathrm{~km}^{-2} \mathrm{y}^{-1}\right)$ and the highveld and Drakensberg mountain range of South Africa $\left(26.4 \mathrm{~km}^{-2} \mathrm{y}^{-1}\right)$. A rate of $15.9 \mathrm{~km}^{-2} \mathrm{y}^{-1}$ was obtained for Gaborone, Botswana, which is in excellent agreement with the results of Mackerras and Darveniza (1994). A relatively significant level of activity was also located off the east coast of South Africa, in proximity to Tihany's conjugate point. The warm Agulhas current, which flows down the east coast of Africa from approximately $27^{\circ}$ to $40^{\circ} \mathrm{S}$, and high pressure systems in the Indian Ocean provide conditions favourable for the formation of thunderstorms in this area. Low lightning activity was observed off the west coast. This is due to the presence of the cold Benguela current, which inhibits convective activity.

Within the study region 219 million flashes occur on average per year, of which $82 \%$ are located in the tropics. This is equivalent to a mean flash rate of $6.9 \mathrm{~s}^{-1}$, partitioned into $6.2 \mathrm{~s}^{-1}$ over land and a oceanic rate of $0.7 \mathrm{~s}^{-1}$. Extrapolating from the flash rate for southern Africa results in a global rate of $121 \mathrm{~s}^{-1}$, which is not significantly different from the customary estimate of $100 \mathrm{~s}^{-1}$ (Brooks, 1925). Christian et al.
(2003), considering lightning data from the OTD between $75^{\circ} \mathrm{S}$ and $75^{\circ} \mathrm{N}$ latitude, obtained an average global flash rate of $44 \pm 5 \mathrm{~s}^{-1}$, while Mackerras et al. (1998) achieved $65 \mathrm{~s}^{-1}$, with a factor 2 uncertainty in either direction, noting that this probably underestimates the true figure. While our projected result lies within the Mackerras et al. (1998) range of uncertainty, it is surely an overestimate as it is based on a region which experiences a flash density well above the global average.

These figures may be contrasted with the mean global stroke rate estimated from WWLLN data which is only around $1.1 \pm 0.2 \mathrm{~s}^{-1}$. This suggests that the efficiency of this system is still comparatively low and that it only recognises strokes of relatively large amplitude or those favourably situated with respect to the limited number of stations distributed over the globe. Undoubtedly the efficacy of WWLLN will increase when additional stations are established in the future.

The majority of lightning occurs over land, with a mean annual land to ocean flash ratio of around 10:1 (Christian et al., 2003). The region of the globe considered by Christian et al. (2003) was $28.3 \%$ land, while the study region here is $36.2 \%$ land. The land-ocean flash ratio in the study region was found to be 8.4:1, comparable to the value obtained by Christian et al. (2003). When the proportion of land and ocean are taken into account, the ratio between the flash rate over land and that over the ocean decreases to 5.5:1. The ratio derived here is reduced by the appreciable level of activity off the south-east coast of the continent, while the result of Christian et al. (2003) is elevated by the low level of activity over the Pacific Ocean and at high latitudes.

A seasonal variation in lightning activity arises from the variation in solar heating through the year. In Fig. 3 the annual flash density data is decomposed into seasonal contributions. The level of activity in the tropics is consistently the highest throughout the year. In the southern reaches of the continent a seasonal variation is more apparent, with a peak during spring and summer. In autumn and winter, with cool and dry conditions, the continental activity recedes to the tropics but a significant level of activity is maintained off the south-east coast of South Africa. The average daily flash rates are given in Table 1.

The association between heating of the air close to the Earth's surface and convection also implies a diurnal variation in lightning activity, where the peak should lag some time behind the Sun passing through the meridian. Focusing now on the whistler source region, the diurnal variation of lightning activity is plotted in Fig. 4. During winter the level of activity is consistently low throughout the day. In spring a minor increase is evident in the afternoon. The effects of diurnal heating are most apparent in the data for summer and autumn, where a pronounced peak exists in the late afternoon, in excellent agreement with Eriksson (1976), who found it to be at around 17:00 South African Standard Time (SAST). The peak is broad, rising at noon and subsiding around midnight. Williams and Heckman (1993), 
(a)

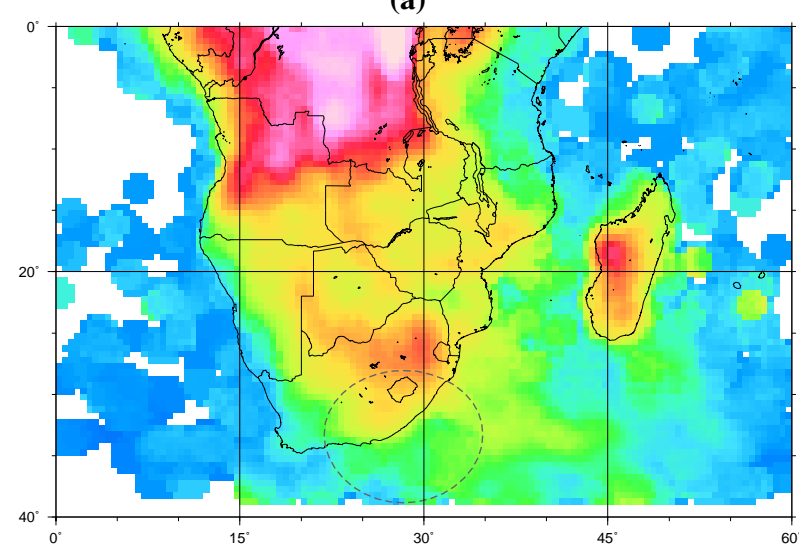

(c)

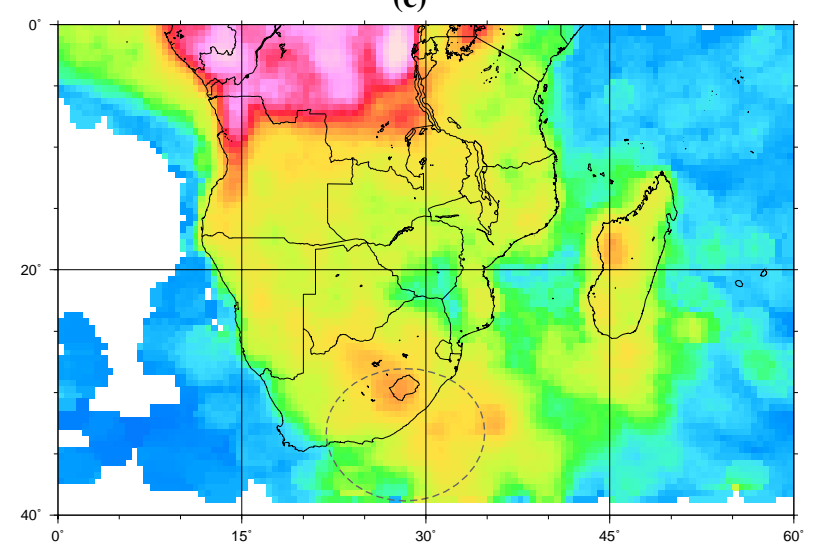

(b)

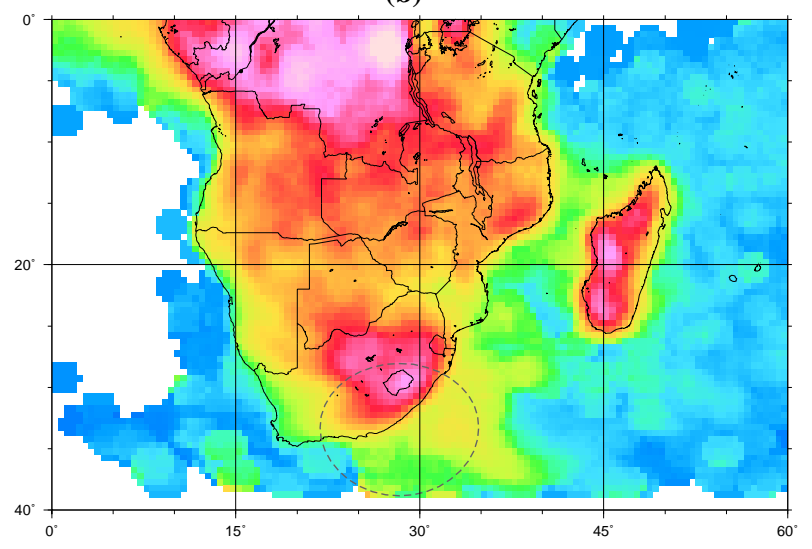

(d)

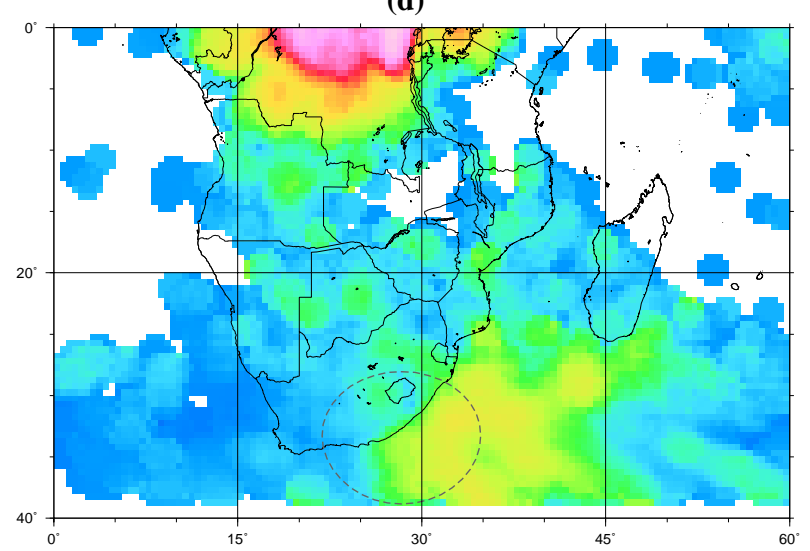

Fig. 3. The seasonal distribution of lightning flash density over southern Africa during (a) spring (September to November), (b) summer (December to February), (c) autumn (March to May) and (d) winter (June to August). The colour scale is identical to that of Fig. 2.

considering data for summer in Darwin, Australia, found a peak in the lightning frequency between 16:00 and 17:00 LT, with a half-width of around $6 \mathrm{~h}$.

In Fig. 4 the diurnal variation in lightning activity in the whistler source region is separated into contributions from storms over land and ocean. Although an afternoon peak is evident over land in all seasons except winter, no systematic diurnal variation is apparent over the ocean. This may be attributed to the larger heat capacity of the ocean, which would ensure that the temperature of the ocean is stable, while the temperature of the land varies appreciably over time scales in the order of 1 day. One might expect that the temperature gradient, and hence the rate of convection, above the ocean would be maximised during the early morning hours when the air temperature reaches a minimum. This, however, is not reflected in the lightning statistics.

The total daily rate for the whistler source region derived from the data in Fig. 4 is also given in Table 1. While an average of $50.9 \times 10^{3}$ flashes per day occur in the source region during summer, this drops to $12.4 \times 10^{3}$ per day in
Table 1. Average daily flash rates $\left(\times 10^{3} \mathrm{~d}^{-1}\right)$ over the entire study region and the whistler source region. The statistics are partitioned into contributions from land and ocean areas. The sum of these contributions is not precisely the rate attributed to the whole due to slight differences in the total viewing time of each area, which produces a non-uniform weighting of the statistics.

\begin{tabular}{lllllll}
\hline & \multicolumn{3}{c}{ study region } & \multicolumn{3}{c}{ whistler source region } \\
\hline season & total & land & ocean & total & land & ocean \\
spring & 642.8 & 600.4 & 42.4 & 19.8 & 12.4 & 6.6 \\
summer & 959.6 & 886.8 & 72.9 & 50.9 & 35.5 & 13.0 \\
autumn & 617.3 & 520.9 & 96.3 & 40.5 & 15.4 & 24.9 \\
winter & 180.2 & 137.3 & 42.9 & 12.4 & 1.2 & 11.6 \\
\hline annual & 600.0 & 536.4 & 63.6 & 31.2 & 16.3 & 14.2 \\
\hline
\end{tabular}

winter. When these rates are split into contributions from land and ocean regions, the resulting statistics reveal that during spring and summer the majority of strokes occur over 
(a)

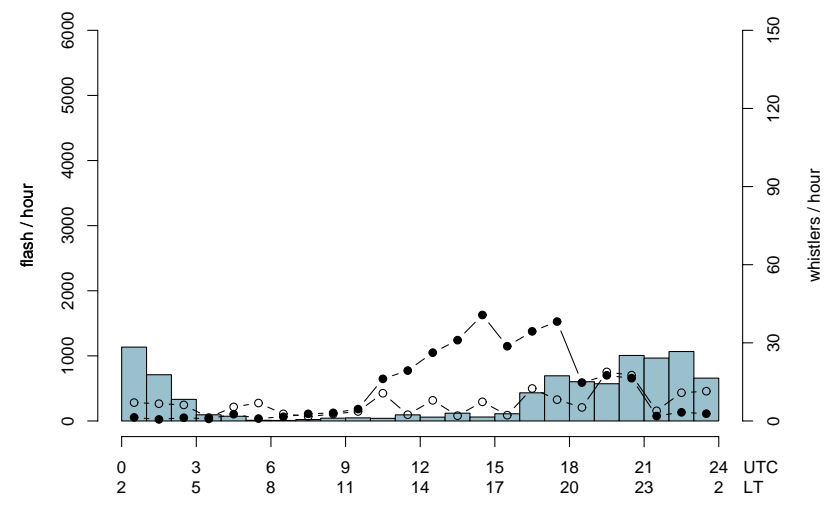

(c)

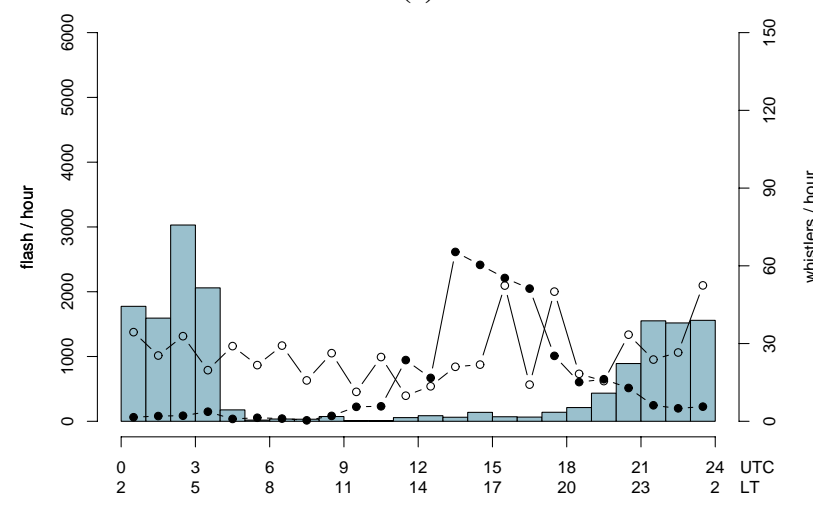

(b)

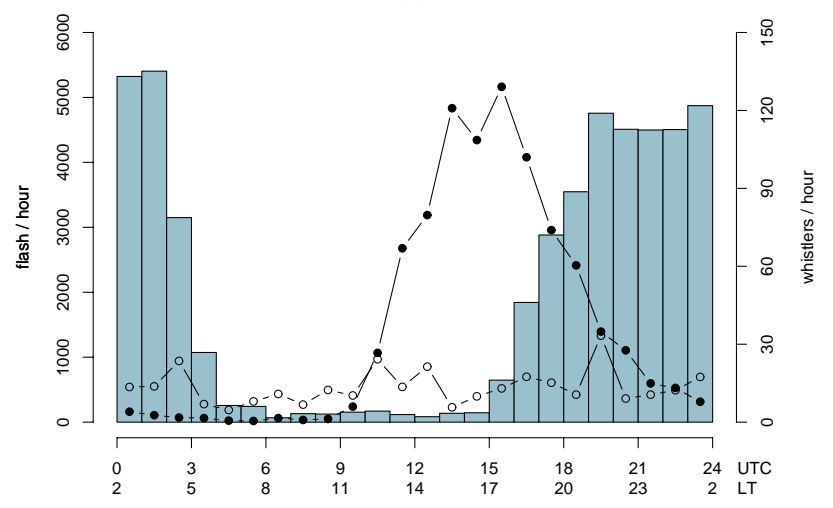

(d)

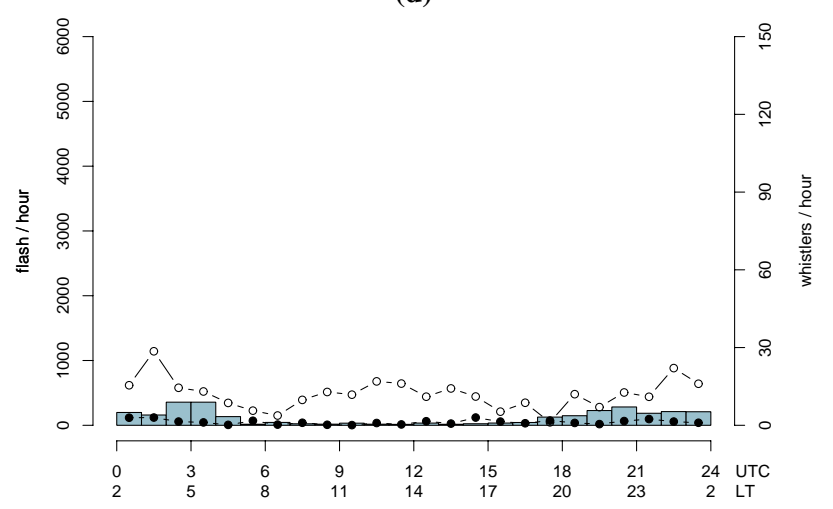

Fig. 4. Diurnal variation of lightning activity in the whistler source region $(\bullet=$ land; $\circ=$ ocean $)$ and the rate of whistler observation at Tihany (bars) as a function of season (a) spring, (b) summer, (c) autumn and (d) winter. Local times are based on the $30^{\circ} \mathrm{E}$ meridian, which corresponds to SAST.

land, whereas during autumn and winter relatively greater activity is found over the ocean.

The annualised daily variation in lightning activity plotted in Fig. 5a is dominated by the contributions from summer and autumn, and hence reflects an activity maximum in the late afternoon and a minimum during the morning hours. In Fig. 5b the diurnal activity is divided into three local time periods: morning (00:00-08:00 SAST), midday (08:00-16:00 SAST) and evening (16:00-24:00 SAST). More than half the lightning flashes occur within the latter portion of the day, consistent with the development of storms over South Africa in the late afternoon and early evening (Preston-Whyte and Tyson, 1988).

The seasonal and inter-annual variation in the daily flash rate within the whistler source region are presented in Fig. 6. Due to the gradual precession of the TRMM platform, a period of around 100 days is required for LIS to view a given location at all local times. As illustrated at the top of Fig. 6 the finite size of the whistler source region ensures that this area is re-sampled more regularly, taking only about 50 days, although all parts of the region may not be re-sampled during this period. A conservative 100 day boxcar average was therefore applied to the data in Fig. 6 to remove aliases of the diurnal cycle. An annual periodicity is immediately apparent, with peaks during the summer and troughs during the winter months.

The effect of the solar cycle on lightning activity is not apparent in Fig. 6. The peak flash rate during year 2000 (solar maximum) is not significantly higher than that for adjacent years and there is no systematic decrease in the level of activity approaching solar minimum. It is, however, quite possible that the effect of the solar cycle would be manifest in statistics for the entire globe or a region closer to the equator.

The annual variation averaged over the six year period is plotted in Fig. 7. The average daily rates are well described by a sinusoid of amplitude $20.3 \times 10^{3} \mathrm{~d}^{-1}$ and mean $31.3 \times 10^{3} \mathrm{~d}^{-1}$. The maximum of the fitted curve occurs on 10 February, while the minimum is on 12 August. The maximum coincides with the peak in average daily maximum temperature at East London, but lags some 51 days behind the solstice. 
The diurnal and seasonal variations in lightning activity have already been discussed separately. It is however illuminating to consider their joint variation over both short and long time scales. To this end the average flash rate is plotted as a function of day number and time of day in Fig. 8a. Here it is readily apparent that the lightning activity is concentrated in the late afternoon during spring and summer, while a low level of activity is maintained consistently at other times. The times of sunrise and sunset at $100 \mathrm{~km}$ altitude are also indicated and it is interesting to note that the peak level of lightning activity declines rather rapidly after sunset.

\section{Whistler statistics}

Continuous broadband digital VLF recordings have been made at Tihany, Hungary, since 27 February 2002. The recording system consists of two perpendicular magnetic loop antennae with areas $\sim 100 \mathrm{~m}^{2}$ orientated geomagnetic north-south and east-west. In principle this apparatus allows the arrival azimuth of a signal to be determined. However, such results are fraught with inaccuracies (Strangeways, 1980; Lichtenberger et al., 1997) and are only practicable for signals which enter the Earth-ionosphere waveguide at a significant distance from the receiver, since these possess a wavefront which is almost vertical. The VLF signals are amplified and then digitised at a sampling rate of $44.1 \mathrm{kHz}$ using a 16 bit sound-card in a personal computer (PC). The PC time is synchronised with the Pulse Per Second (PPS) signal of a GPS receiver. The PPS timing accuracy is better than $1 \mu \mathrm{s}$, which is smaller than the data sampling period $(\sim 22 \mu \mathrm{s})$.

Whistler traces are automatically identified in the incoming data stream. The whistler detection algorithm is based on two-dimensional image correlation: dynamic spectra are computed for $16 \mathrm{~s}$ overlapping data windows and correlated with a pattern made from a model whistler. The model whistler is based on Bernard's (1973) approximation and covers the dispersion range $20-80 \mathrm{~s}^{1 / 2}$. The choice of this range is based on the average dispersion, $\langle D\rangle=45 \mathrm{~s}^{1 / 2}$, for whistlers recorded in Tihany. The frequency range considered is from 4.5 to $11 \mathrm{kHz}$, the upper limit being imposed because of interference from powerful transmitters in Europe and Asia. The algorithm applies various techniques to remove the effects of unwanted signals including spherics, power line harmonics, and military and navigation VLF transmitters. Several tunable parameters - the frequency and dispersion range, and the detection threshold - allow the algorithm to be customised to observations at different sites. Adaptive noise averaging makes it possible to detect very faint and swishy whistler traces. Generally these faint traces are not suitable for further analysis, however they are important for statistical studies. Data sequences of $4 \mathrm{~s}$ duration containing the detected whistlers are saved together with the time of arrival of the traces. The algorithm runs 8-10 times faster than real time on a P4 $(1.8 \mathrm{GHz}) \mathrm{PC}$, thus it is capable (a)

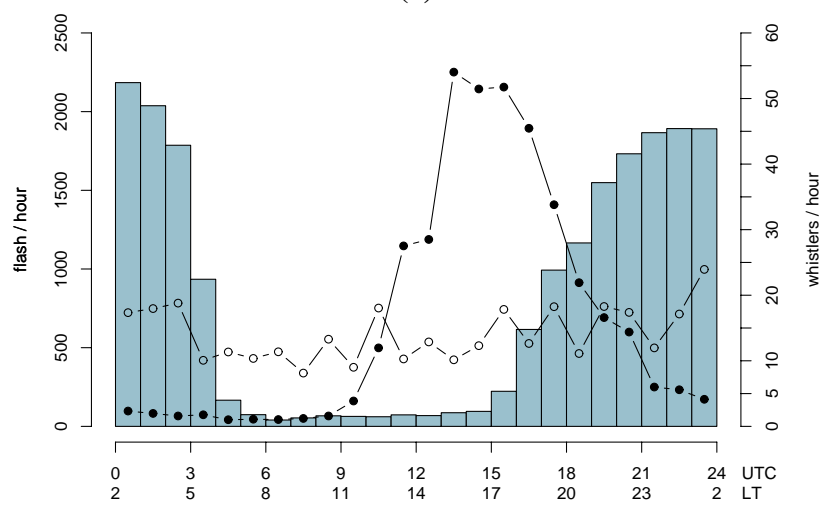

(b)

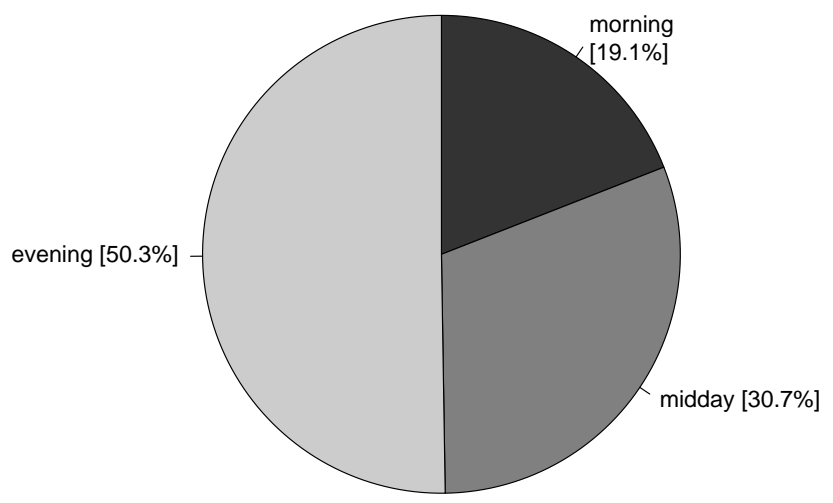

Fig. 5. (a) Annualised diurnal variation of lightning flash rate in the whistler source region $(\bullet=$ land; $\circ=$ ocean $)$ compared with whistler rate at Tihany (bars). (b) Distribution of lightning flashes in the whistler source region divided into morning (00:0008:00 SAST), midday (08:00-16:00 SAST) and evening (16:0024:00 SAST) periods.

of scanning different dispersion ranges simultaneously or it could be combined with automatic analysis software to supply the propagation $L$-value and plasma parameters. The latter software is currently under development.

The whistler detection algorithm should still be considered as experimental and, as such, its efficiency is still not fully established. A number of factors are involved in determining its performance. Spurious events may arise from signals which exhibit whistler-like dispersion over a limited frequency range but are not generated by lightning. The number of such specious incidents logged by the system may be adjusted by means of a detection threshold. A low threshold will result in almost $100 \%$ efficiency for genuine whistlers but around $95 \%$ of illegitimate signals which match the dispersion criteria are also logged. A higher threshold allows a detection efficiency of $95 \%$ for authentic whistlers but only $80 \%$ for conforming but invalid events. It is also possible that 
I: I

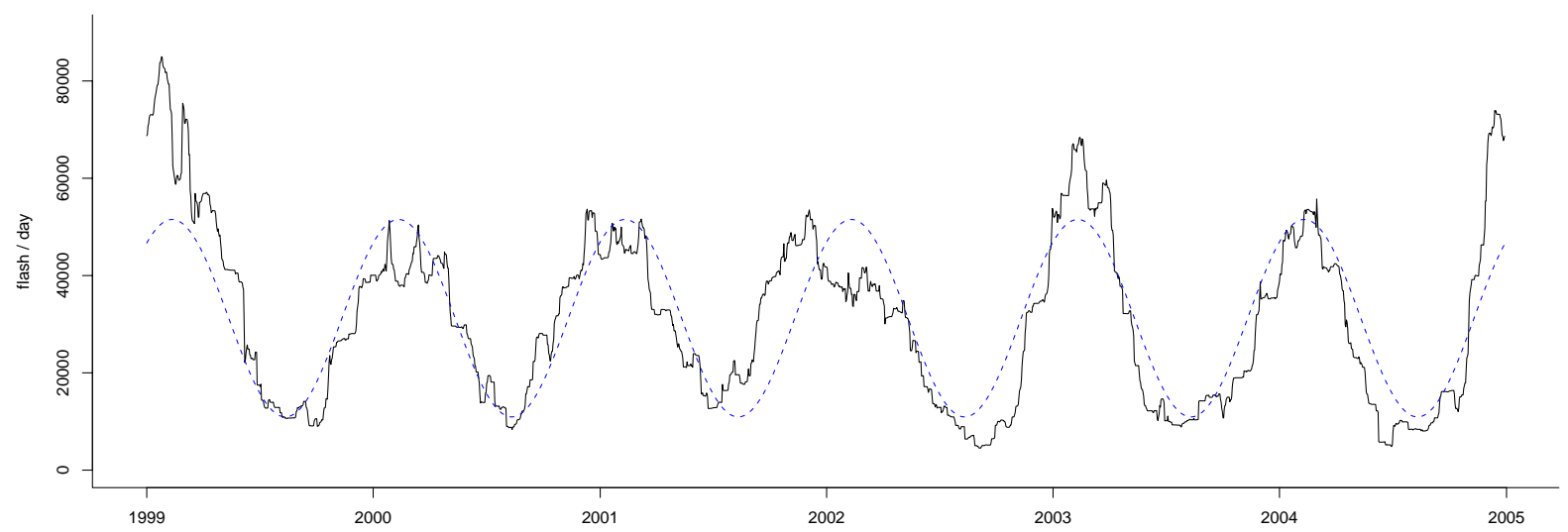

Fig. 6. Daily lightning flash rates in the whistler source region. The upper panel indicates the local time at which TRMM was over the source region.

the system may fail to detect legitimate whistlers. This might occur under any of the following circumstances: the whistler has low amplitude in the detection frequency range; the whistler occurs on a file boundary (almost insignificant for hour-long sample files); or the whistler coincides with a relatively strong impulsive noise (other than a typical spheric, the effects of which are filtered out). The efficacy of the algorithm, although not rigorously quantified, is thus thought to be high for typical whistlers with a reasonable signal-tonoise ratio.

Whistler counts for the period 27 February 2002 to 27 February 2004 have been compiled. During these two years more than 368000 whistler events were logged. Each event should, in principle, correspond to a distinct whistler trace. The median temporal separation of successive events was found to be $0.33 \mathrm{~s}$. A relatively large fraction of these events, some $6.1 \%$, were separated by $10 \mathrm{~ms}$, which is the resolution at which the event times were recorded. Now it is probable that these narrowly separated events are in fact duplicates generated by the same trace. This could occur for weak traces with amplitudes close to the threshold, in which case a ripple on the peak might exceed the threshold a number of times. Because these events are questionable they have been consolidated into single instances, and subsequently only around 345000 whistler events remained. However, it is evident that many densely clustered events still persist. Since multi-trace whistlers, following numerous distinct paths through the magnetosphere, are rare at low $L$, it is likely that these arise from multiple consecutive strokes and propagate along the same or similar paths.

The diurnal and seasonal variation in whistler detection frequency are displayed in Figs. 5a and 7, respectively. The diurnal peak occurs between 18:00 and 03:00 UTC, while the seasonal maximum appears in February. The corresponding variations obtained by Tarcsai et al. (1988) between 1970 and 1975 from Tihany data are in reasonable agreement with the ones presented here, showing a seasonal maximum in March and April, and a diurnal peak between 15:00 and 03:00 UTC, although their peak is heavily skewed towards the first part of this interval. The cause of the discrepancies is probably the fact that the results of Tarcsai et al. (1988) were derived from data sampled with the classical two minute per hour recording scheme and were based on only 1332 whistlers, $60 \%$ of which were recorded between March and April 1973. Thus the distribution of these data might be misleading in that the peaks may arise from a few large storms. The goal of that study was also not to collect statistics, but to obtain plasmaspheric electron densities from whistler traces. Because of the nature of the manual scaling procedure and the requirements of the analysis method used to determine plasma and propagation parameters (Tarcsai, 1975) that study required long, clear whistler traces. Whistlers were thus selected to conform to these requirements and weak, short or diffuse traces were discarded, making the diurnal and seasonal statistics less significant.

The diurnal variation of whistlers in Fig. 5a is shifted to later local times with respect to the lightning curve. In Fig. 4 it is apparent that this is the case for all seasons except winter, where the number of detected whistlers seems too low to make significant conclusions. It is remarkable that the decrease of whistler occurrence in the morning around 03:00 UTC is much faster than the afternoon increase around 16:00 UTC though this is the period of most vigorous lightning activity. Thus the presence of source lightning is a necessary, but not sufficient condition for whistlers. Propagation circumstances must also play an important role: penetration 


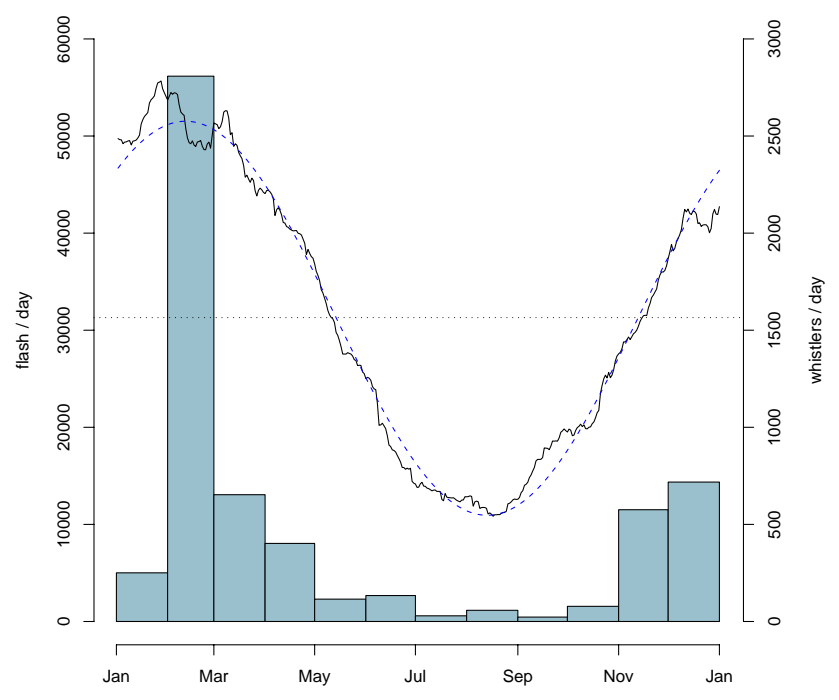

Fig. 7. Average daily lightning stroke rates within the whistler source region (curve) and monthly average whistler rates at Tihany (bars).

of the electromagnetic radiation generated by the lightning strokes through the ionosphere and into the magnetosphere; the presence of plasmaspheric ducts and the refraction of the dispersed wave packet into the Earth-ionosphere waveguide in the opposite hemisphere.

The seasonal variation plotted in Fig. 7 shows good agreement with LIS data except for the large peak in February. If one takes into account the fact that a significant fraction of this peak ( $\sim 65000$ events) is the contribution of four extremely active days (day numbers 45 and 50 in 2003 and 57-58 in 2004), the agreement between the seasonal variation of lightning flashes and whistlers is improved. The origin of these highly active days is not clear at the moment: do they arise from extreme lightning activity or because of exceptional propagation conditions? In an attempt to assess this issue, the WWLLN data for the source region are plotted along with the whistler counts in Fig. 9. It should be noted that the number of whistlers substantially exceeds the number of lightning strokes. This is, however, to be expected due to the low efficiency of the WWLLN. On day 57 the heightened whistler activity was only observed after 18:00 UTC, which coincides with the stroke count maximum. Other days however have a similar or greater number of strokes during this interval but apparently do not result in a comparable number of whistlers. Of course, it is possible that more whistlers were produced on these other days but that the detection algorithm failed to identify them. Alternatively, the strokes may have been of a lower amplitude or less favourably situated to excite a duct.

The geographical distribution of the strokes during the interval 18:00 to 24:00 UTC on the four most active days of February 2004 is plotted in Fig. 10. It is interesting to (a)

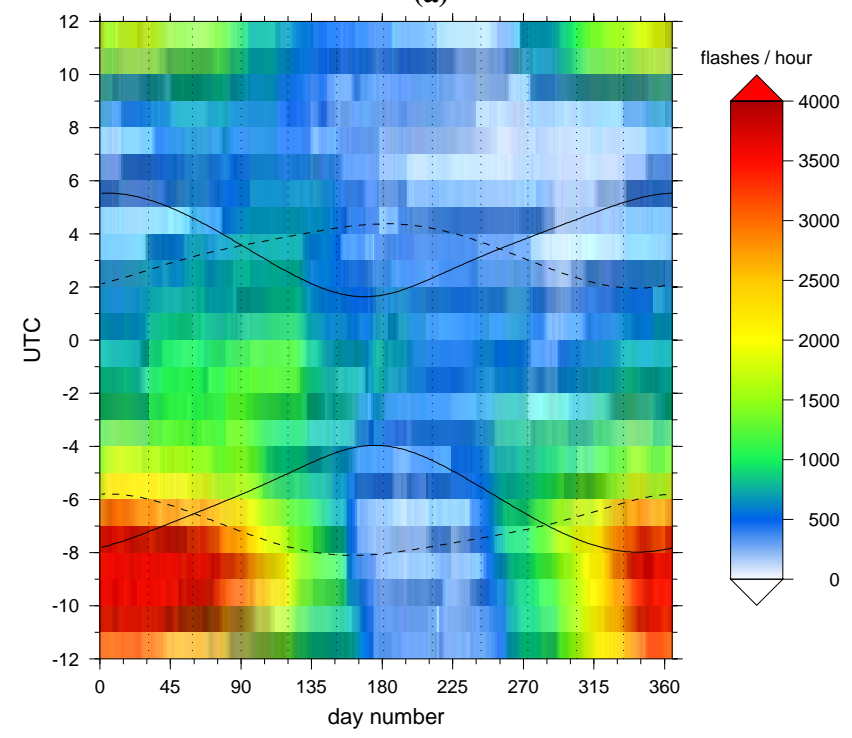

(b)

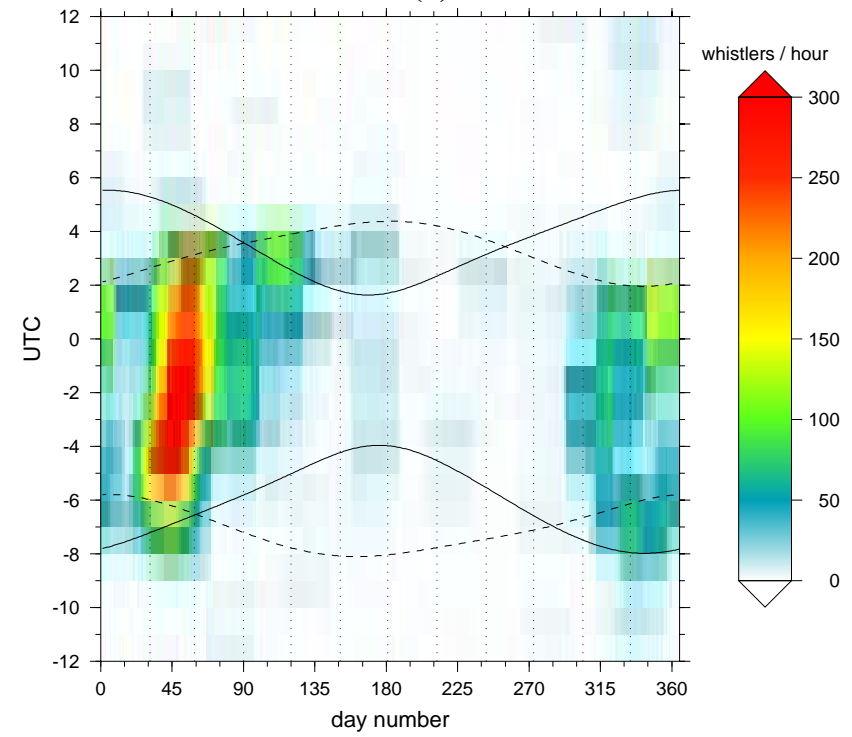

Fig. 8. Average (a) lightning and (b) whistler occurrence rates as a function of UTC and day number. The centre of the $y$-axis is shifted to midnight UTC so that, for instance, -2 corresponds to 22:00 UTC. Solid curves indicate the passage of the terminator at an altitude of $100 \mathrm{~km}$ over Tihany, while the dashed curves apply to the conjugate point.

observe that, whereas on days 36,41 and 50 , the strokes were at latitudes lower than the conjugate point, on day 57 two storms were located poleward of the conjugate point. Tarcsai et al. (1988) observed that the majority, some $80 \%$, of whistlers recorded at Tihany travelled along ducts at higher $L$-value than the station. This may in part be due to the smaller ionospheric optical depth at higher latitudes 

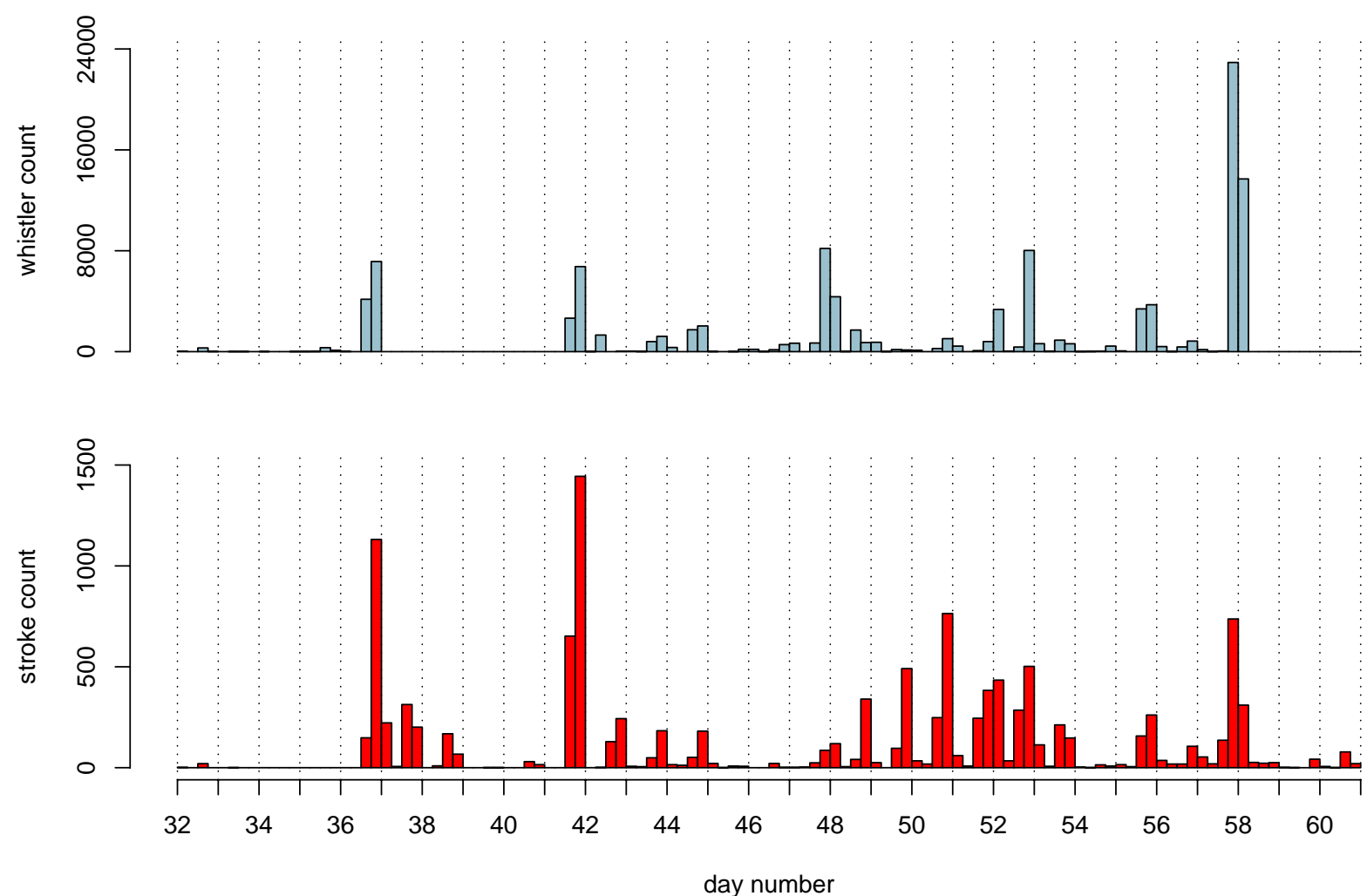

Fig. 9. Comparison of WWLLN stroke counts in the source region and whistler counts at Tihany for February 2004. Each day is divided into four $6 \mathrm{~h}$ intervals.

where the field lines have a greater inclination. In this case though the elevated whistler production efficiency on day 57 might be attributed to better matching between the Earthionosphere waveguide and ducts with footprints at lower latitudes than the lightning strokes (Helliwell, 1965, p. 57).

The occurrence of whistlers through the year and as a function of time of day is highly irregular. Consequently, even averaging 2 years of whistler data results in a distribution which is distinctly fragmentary and does not give a fair representation of the variation in whistler incidence. The data are therefore processed as follows to create Fig. 8b: the observed whistler frequency is binned as a function of day and hour number; the resulting matrix is then boxcar averaged along the day number axis.

In Fig. 8 the passage of the terminator over Tihany and it's conjugate point is indicated. The vast majority of whistlers, $85 \%$ and $89 \%$, are recorded when the source region and Tihany respectively are in darkness. One may conclude that the effect of solar irradiation on the atmosphere, notably the enhancement of the lower regions of the ionosphere, is to inhibit the transmission of whistlers. The ionosphere is evidently more transparent to VLF waves when not illuminated by the Sun (Volland, 1995a). It is not possible on the basis of the data in Fig. $8 \mathrm{~b}$ to determine whether this is effected in the ionosphere above the source or receiver.

The terminator curves apply precisely to the receiver and its conjugate point. Although the passage of the terminator may be abrupt at a given point, it takes a finite time to traverse the extended region surrounding the source and receiver. Due to the fact that whistlers may enter the ionosphere or emerge from it at points distant from Tihany or its conjugate, one should appreciate that the effect of the terminator would be smeared out over a finite time. The motion of the terminator progressively reduces or increases the effective area of the source region - or equivalently the receiver region. The inclination of the terminator should also have an effect on the rate at which this transition occurs, being more rapid during autumn and spring, when the terminator is more closely aligned with the dawn and dusk meridians.

In Fig. 11 the diurnal and seasonal variation is unified in a single plot of the whistler/flash ratio, $R$. It should be noted that whistlers are generated by lightning strokes, and multiple whistler events may thus arise from a single flash, so that $R$ is not an optimal parameter. However, since the first few strokes in a flash carry the most current, these are most likely to give rise to a whistler and thus one would expect that the whistler/stroke ratio should scale with $R$. Although the values of $R$ should not be interpreted too literally, since 
(a)

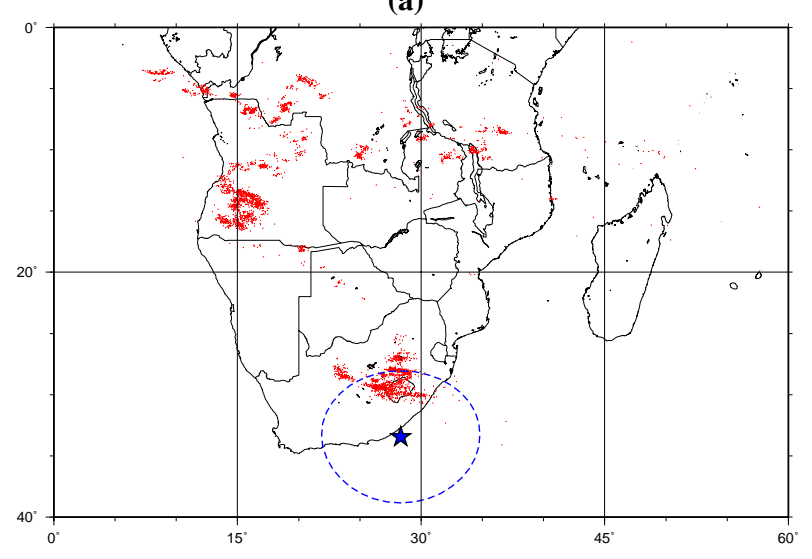

(c)

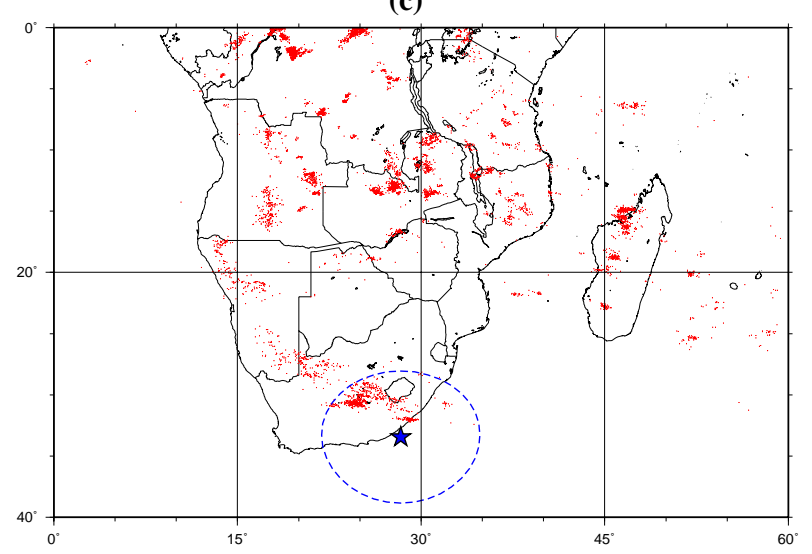

(b)

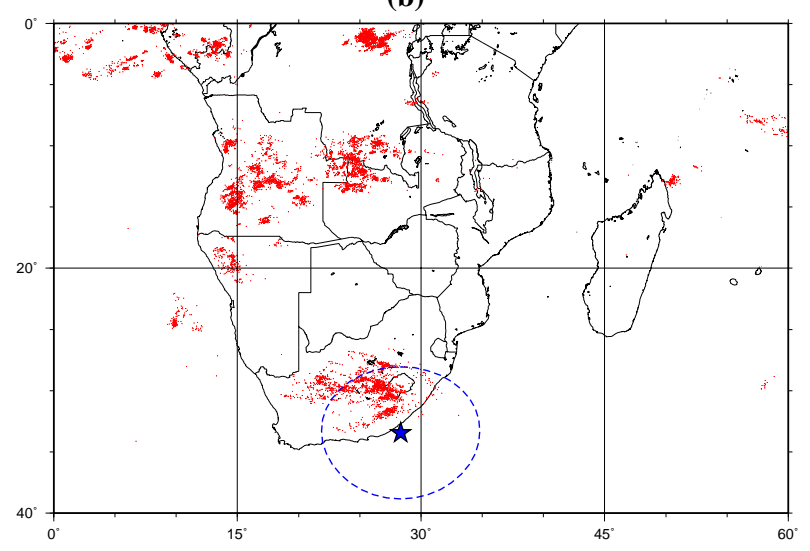

(d)

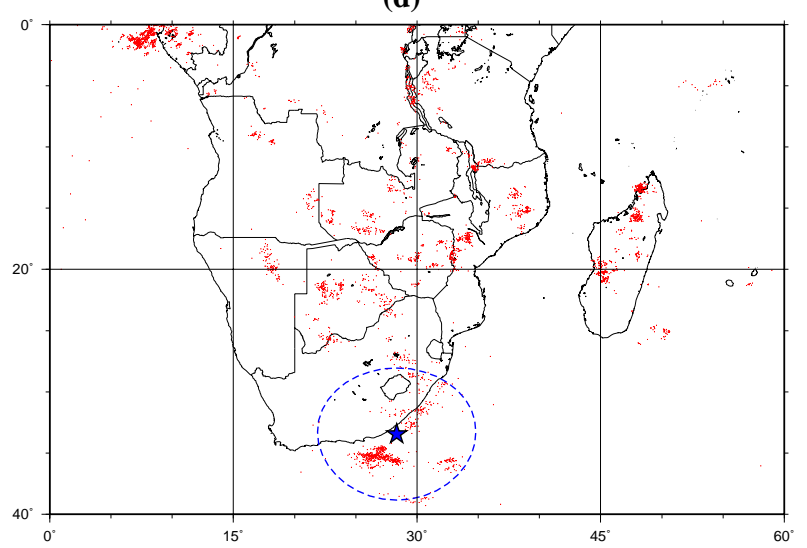

Fig. 10. Distribution of strokes detected by WWLLN during the interval 18:00 to $24: 00$ UTC on (a) day 36 , (b) day 41, (c) day 50 and (d) day 57 during 2004.

they depend directly on the size of the assumed source region, they do reflect the variation in the relative efficiency of lightning discharges in generating detectable whistlers in the opposite hemisphere. Figure 11 clearly shows the effect of ionospheric illumination. During the austral summer, where lightning activity peaks in the afternoon, the incidence of whistlers only becomes appreciable after sunset. $R$ increases as first the ionosphere above the receiver, and then that over the source, go into darkness. $R$ continues to rise as the ionospheres at both ends of the whistler path become more transparent, and finally the peak is reached after midnight. This peak occurs several hours before sunrise in either region. It might be argued that $R$ decreases as first the ionosphere over the source and then over the reception region become progressively more illuminated. A study of the profile of the terminator as it crosses the source region shows that this begins to happen at about 02:00 UTC during the austral summer.

The question of which ionosphere (source or receiver) is operative in determining the probability of whistler occurrence is not resolved here as the periods of darkness at both ends of the field line overlap for the interval of appreciable whistler activity. A similar study based on whistler statistics for a high latitude station, preferably one within the polar circles, would likely resolve this issue.

A remarkable feature of Fig. 11 is the fact that the peak in $R$ is narrowly confined between days 30 and 75 with more moderate values occurring between days 300 and 360 . Since the definition of $R$ effectively eliminates the diurnal and seasonal variation in lightning activity, a naive view would suggest that it should be broadly similar at a given local time throughout the year subject to modulations introduced by changes in the location of the terminator. If whistler occurrence simply depended on the probability of transmission through the ionosphere then one would expect $R$ to be fairly constant at similar levels of ionospheric illumination. The fact that this is not the case suggests that other factors influence the generation and/or reception of a whistler. There are at least 3 possible reasons for this:

1. One might argue that the generation of whistlers creates or enhances the ducts in which the signals propagate. The calculations of Park and Helliwell (1971) 


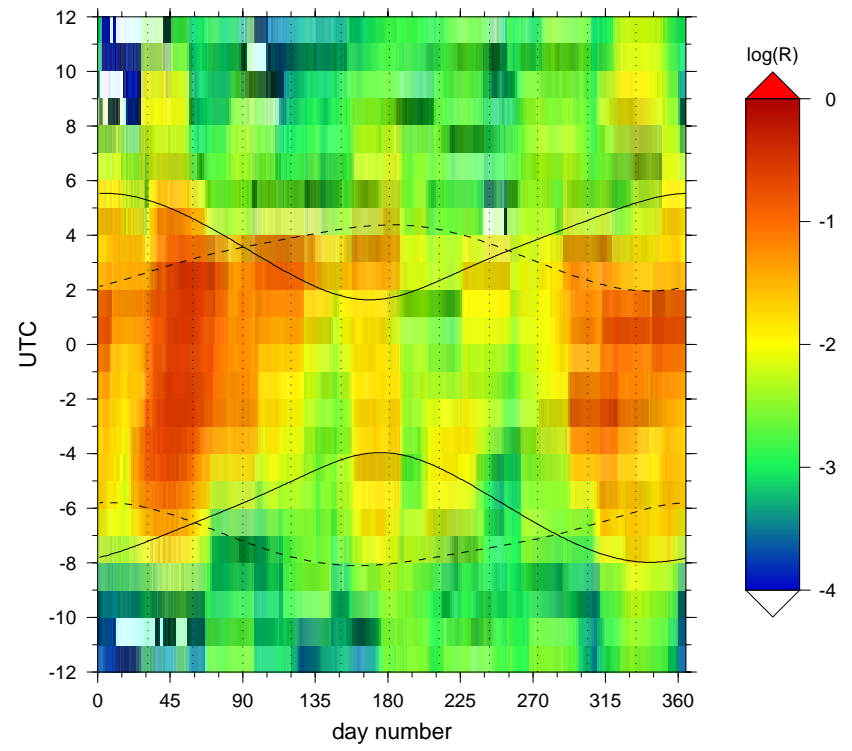

Fig. 11. Whistlers per Lightning Imaging Sensor flash as a function of UTC and day number. In order to extend the range of information, $\log R$ rather than $R$ is plotted.

indicate that a duct may form as the result of thunder cloud electric fields. While experimental observations (Clilverd et al., 2001) suggest that this mechanism does not play a significant role in duct formation, theoretical calculations (McCormick et al., 2002) reveal that it may be active in some situations. It is possible that duct formation may be enhanced by the strong lightning activity during summer afternoons, producing favourable conditions for whistler propagation later that night. A difficulty with this explanation is that the peak in lightning activity is broad, extending from about day 300 to 135, whereas the peak in $R$ is narrow. The fact that the days of high lightning activity correspond to days of high whistler rates, even though the peak in lightning is at an earlier time, might suggest that this may make a contribution even though it is unlikely to be the complete explanation. If this mechanism is valid then it would also explain the low incidence of whistlers between June and September.

2. The lightning may change in character throughout the season. For example, if whistlers are predominantly produced by CG strokes, and these are more prevalent at times of high $R$, then this would explain the observations. Alternatively the lightning may be more intense at times that correspond to high $R$. We do not have enough information in this study to assess this explanation.

3. Perhaps the most plausible candidate is the location of the lightning. To test this possibility we have looked at the location of lightning strokes using data from WWLLN for February 2004. The comparison between strokes in the source region and whistlers at Tihany is given in Fig. 9. The WWLLN system clearly does not detect all lightning strokes because on many occasions the number of whistlers exceeds the number of strokes. An interesting feature emerges if one looks at the location of the strokes on days 36, 41, 50 and 57 (Fig. 10), days with many lightning strokes. We confine our attention to the 6 hours before midnight. On day 57 the whistler to flash ratio is exceptionally high and only on this day are there a large number of strokes on the high latitude side of the conjugate point. This would be consistent with the fact that the wave normals of waves travelling from higher latitudes, after refraction in the ionosphere lie closer to the magnetic field direction and therefore may couple more easily to whistler ducts. This point needs further investigation as other trapping scenarios are also possible.

It is still not clear whether the modification of the ionosphere across the terminator or the presence and formation of ducts are ultimately responsible for determining the pattern of whistler occurrence. However, detailed analyses of the lightning-whistler connection are likely to shed further illumination on this question.

\section{Conclusions}

Within southern Africa lightning activity is concentrated predominantly in the tropics, but large contributions are also made over South Africa and Madagascar. Inter-seasonal comparison indicates maximum activity during spring and summer, where the most vigorous period occurs in the late afternoon.

Seasonal variations are most marked at medium latitudes, with maximum activity occurring in the spring and summer over land in South Africa and Madagascar. Within South Africa peak activity is found in the Drakensberg mountains and Lesotho, with only slightly less activity in the highveld. A notable exception to this is a region off the east coast where activity maximises in the autumn and is lowest during spring. Tihany's conjugate point lies within this offshore region. The diurnal variation in lightning activity has a pronounced peak in excess of 5200 flashes/h between 14:00 and 20:00 SAST in summer. This declines to less that 1200 flashes/h in winter.

A considerable level of persistent lightning incidence was observed off the east coast of South Africa and is thought to be caused by the warm waters of the Agulhas current. A similar effect is apparent over the Gulf Stream (Biswas and Hobbs, 1990).

Whistler occurrence in Tihany peaks in February, the month in which lightning activity is a maximum in the source region. However the whistler pattern is not directly related 
to lightning activity as the diurnal peak in whistler incidence occurs between 20:00 and 03:00 SAST, whereas the peak in conjugate lightning activity occurs between 14:00 and 20:00 SAST. Helliwell (1965) noted that whistlers were most frequently observed during the night, suggesting that their passage through the ionosphere was attenuated during daylight by absorption in the $\mathrm{D}$ region. The diurnal variation in whistler activity reported here is similar to that recorded at higher latitude stations (Helliwell, 1965) where the greatest activity occurs during the night, with a maximum before dawn.

Seasonal variations in whistler activity were first reported by Storey (1953), and Helliwell (1965) showed that whistler activity at Byrd station was closely related to thunderstorm activity measured in terms of thunderstorm days. However, our measurements show a connection between whistlers and lightning that is modified by ionospheric absorption. This modification can be clearly seen where the afternoon onset of whistler activity appears to be essentially defined by the terminator. The decline in activity in the morning hours is not as well defined by the morning terminator, but this can be explained by the reduced frequency of source lightning during the morning hours.

We have attempted to isolate the effects of ionospheric absorption by looking at the whistler/flash ratio (Fig. 11) but the problem will only be resolved by establishing a direct correspondence between a given set of whistlers and the location and magnitude of their causative lightning strokes. This may be possible in the future when the WWLLN is complete. The present status of this network may be determined by visiting http://webflash.ess.washington.edu/.

Acknowledgements. Lightning data for this study were obtained from the Global Hydrology Resource Center (http://ghrc.msfc.nasa. gov) and from the World Wide Lightning Location Network. The collaboration between the University of KwaZulu-Natal and the Eötvös University is supported by the National Research Foundation (NRF) of South Africa and the Hungarian Ministry of Education under the Hungarian-South African Intergovernmental Science \& Technology Cooperation Programme.

Topical Editor M. Pinnock thanks C. Rodger and another referee for their help in evaluating this paper.

\section{References}

Anderson, R. B., Van Niekerk, H. R., Kroninger, H., and Meal, D. V.: Development and field evaluation of a lightning earth-flash counter, IEE Proc., 131A, 118-124, 1984.

Bernard, L. C.: A new nose extension method for whistlers, J. Atmos. Terr. Phys., 35, 871-880, 1973.

Biswas, K. R. and Hobbs, P. V.: Lightning over the Gulf Stream, Geophys. Res. Lett., 17, 941-943, 1990.

Brooks, C. E. P.: The Distribution of Thunderstorms over the Globe, Geophys. Memo., 3, 147-164, 1925.
Carpenter, D. L. and Orville, R. E.: The Excitation of Active Whistler Mode Signal Paths in the Magnetosphere by Lightning: Two Case Studies, J. Geophys. Res., 94, 8886-8894, 1989.

Christian, H. J., Blakeslee, R. J., Boccippio, D. J., Koshak, W. J., Goodman, S. J., and Mach, D. M.: Science Data Validation Plan for the Lightning Imaging Sensor (LIS), Tech. rep., George C. Marshall Space Flight Center, 2000.

Christian, H. J., Blakeslee, R. J., Boccippio, D. J., Boeck, W. L., Buechler, D. E., Driscoll, K. T., Goodman, S. J., Hall, J. M., Koshak, W. J., Mach, D. M., and Stewart, M. F.: Global frequency and distribution of lightning as observed from space by the Optical Transient Detector, J. Geophys. Res., 108, doi:10.1029/2002JD002347, 2003.

Clilverd, M. A., Thomson, N. R., and Smith, A. J.: Observation of two preferred propagation paths for whistler mode VLF signals received at a non-conjugate location, J. Atmos. Terr. Phys., 54, 1075-1079, 1992.

Clilverd, M. A., Rodger, C. J., Thomson, N. R., and Yearby, K. H.: Investigating the possible association between thunderclouds and plasmaspheric ducts, J. Geophys. Res., 106, 29771$29781,2001$.

Dowden, R. L., Brundell, J. B., and Rodger, C. J.: VLF lightning location by time of group arrival (TOGA) at multiple sites, J. Atmos. Solar-Terr. Phys., 64, 817-830, 2002.

Eriksson, A. J.: The measurement of lightning and thunderstorm parameters: Results for the 1975/76 season, Tech. Rep. ELEK 103, CSIR special report, Pretoria, Republic of South Africa, 1976.

Green, J. L., Boardsen, S., Garcia, L., Taylor, W. W. L., Fung, S. F., and Reinisch, B. W.: On the origin of whistler mode radiation in the plasmasphere, J. Geophys. Res., 110, doi:10.1029/2004JA010495, 2005.

Helliwell, R. A.: Whistlers and Related Ionospheric Phenomena, Stanford University Press, 1965.

Johnson, M. P., Inan, U. S., and Lauben, D. S.: Subionospheric VLF Signatures of Oblique (Nonducted) Whistler-Induced Precipitation, Geophys. Res. Lett., 26, 3569-3572, 1999.

Kandalgaonkar, S. S., Tinmaker, M. I. R., Kulkarni, J. R., and Nath, A.: Diurnal variation of lightning activity over the Indian region, Geophys. Res. Lett., 30, doi:10.1029/2003GL018005, 2003.

Koshak, W. J., Stewart, M. F., Christian, H. J., Bergstrom, J. W., Hall, J. M., and Solakiewicz, R. J.: Laboratory Calibration of the Optical Transient Detector and the Lightning Imaging Sensor, J. Atmos. Ocean. Tech., 17, 905-915, 2000.

Lauben, D. S., Inan, U. S., and Bell, T. F.: Poleward-displaced electron precipitation from lightning-generated oblique whistlers, Geophys. Res. Lett., 26, 2633-2636, 1999.

Lichtenberger, J., Tarcsai, G., Hamar, D., Smith, A. J., and Yearby, K. H.: Two and three component direction-finding computations on whistlers using the Matched Filtering and Parameter Estimation method, J. Atmos. Solar-Terr. Phys., 59, 1061-1072, 1997.

Mackerras, D. and Darveniza, M.: Latitudinal variation of lightning occurrence characteristics, J. Geophys. Res., 99, 10 813-10 822, 1994.

Mackerras, D., Darveniza, M., Orville, R. E., Williams, E. R., and Goodman, S. J.: Global lightning: Total, cloud, and ground flash estimates, J. Geophys. Res., 103, 19791-19 808, 1998.

Malan, D. J.: Physics of Lightning, The English Universities Press, 1963.

McCormick, R. J., Rodger, C. J., and Thomson, N. R.: Re- 
considering the effectiveness of quasi-static thunderstorm electric fields for whistler duct formation, J. Geophys. Res., 107, doi:10.1029/2001JA009219, 2002.

Park, C. G. and Helliwell, R. A.: The formation of field-aligned irregularities in the magnetosphere, Radio Sci., 6, 299-304, 1971.

Prentice, S. A. and Mackerras, D.: The Ratio of Cloud to CloudGround Lightning Flashes in Thunderstorms, J. Appl. Meteor., 16, 545-550, 1977.

Preston-Whyte, R. and Tyson, P.: The Atmosphere and Weather of Southern Africa, Oxford University Press Southern Africa, 1988.

Rodger, C. J., Brundell, J. B., Dowden, R. L., and Thomson, N. R.: Location accuracy of long distance VLF lightning location network, Ann. Geophys., 22, 747-758, 2004a.

Rodger, C. J., McCormick, R. J., and Clilverd, M. A.: Testing the importance of precipitation loss mechanisms in the inner radiation belt, Geophys. Res. Lett., 31, doi:10.1029/2004GL019501, $2004 b$.

Rodger, C. J., Brundell, J. B., and Dowden, R. L.: Location accuracy of VLF World-Wide Lightning Location (WWLL) network: Post-algorithm upgrade, Ann. Geophys., 23, 277-290, 2005.

Ruhnke, L. H. and Latham, J. (Eds.): Proceedings in Atmospheric Electricity, A. Deepak Publishing, 1983.

Storey, L. R. O.: An Investigation of Whistling Atmospherics, Phil. Trans. Roy. Soc., A-246, 113-141, 1953.

Strangeways, H. J.: Systematic errors in VLF direction-finding of whistler ducts-I, J. Atmos. Terr. Phys., 42, 995-1008, 1980.
Strangeways, H. J. and Rycroft, M. J.: Trapping of whistler-waves through the side of ducts, J. Atmos. Terr. Phys., 42, 983-994, 1980.

Strangeways, H. J., Rycroft, M. J., and Jarvis, M. J.: Multi-station VLF direction-finding measurements in eastern Canada, J. Atmos. Terr. Phys., 44, 509-522, 1982.

Tarcsai, G.: Routine whistler analysis by means of accurate curve fitting, J. Atmos. Terr. Phys., 37, 1447-1457, 1975.

Tarcsai, G., Szemerédy, P., and Hegymegi, L.: Average electron density profiles in the plasmasphere between $L=1.4$ and 3.2 deduced from whistlers, J. Atmos. Terr. Phys., 50, 607-611, 1988.

Volland, H.: Longwave Sferics Propagation within the Atmospheric Waveguide, in Volland (1995b), chap. 3, 65-93, 1995a.

Volland, H. (Ed.): Handbook of Atmospheric Electrodynamics, vol. II, CRC Press, 1995 b.

Watkins, N. W., Clilverd, M. A., Smith, A. J., Rodger, C. J., Bharmal, N. A., and Yearby, K. H.: Lightning atmospherics count rates observed at Halley, Antarctica, J. Atmos. Solar-Terr. Phys., 63, 993-1003, 2001.

Weidman, C. D., Krider, E. P., Park, C. G., and Blockley, B.: Correlated Measurements of Lightning Radiation Fields and Whistlers, in: Ruhnke and Latham (1983), 334-337, 1983.

Williams, E. R.: The Schumann resonance: A global tropical thermometer, Science, 256, 1184-1187, 1992.

Williams, E. R. and Heckman, S. J.: The Local Diurnal Variation of Cloud Electrification and the Global Diurnal Variation of Negative Charge on the Earth, J. Geophys. Res., 98, 5221-5234, 1993. 